\title{
Iron loss analysis and calculation of high energy density permanent magnet machine
}

\author{
Yangyang Zhao ${ }^{1}, \mathrm{Xu}$ Zhang $^{1}$, Peihao Zhu ${ }^{2,3}$, Qingchun Zheng ${ }^{1,2,3 *}$
}

\begin{abstract}
It is a research hotspot of electric propulsion system that a high energy density permanent magnet machine is used as its main power. In general, the power system of electric propulsion consists of batteries, inverters and high energy density permanent magnet machines and loads. Based on harmonic effect of PWM sine alternating current generated by inverter, iron loss model of high energy density permanent magnet machine is established under inverter power harmonic, and iron loss calculation flow chart of high energy density permanent magnet machine for electric propulsion system is shown. The influences of different stator outer diameter and rotor inner diameter on iron loss are analyzed by using the finite element method. Through the above analysis, a $30 \mathrm{~kW}$ high energy density permanent magnet machine was designed. Then the noload test and iron loss separation test were carried out, verifying that the machine has very low core loss.
\end{abstract}

K e y w or d s: high energy density, permanent magnet machine, iron loss, eddy current loss, hysteresis loss

\section{Introduction}

Electric propulsion systems applied in electric aircraft, electric vehicles and electric ships use electric machines as main power. Compared with internal combustion engines, electric propulsion systems have a series of advantages such as pollution-free, low noise and high efficiency. Therefore, the study of electric machine technology for electric propulsion system has important practical significance and good application prospects.

On account of the bottleneck of current battery technology, its energy density is still not high enough. In order to enhance the endurance, reduce the weight and increase energy density, the main drive electric machine of propulsion system needs to be as small as possible. To achieve this goal, it is a research direction to choose permanent magnet machine as its main drive.

Generally, the electromagnetic load of main drive electric machine of propulsion system is higher than ordinary machine. As a result, the saturation degree of magnetic circuit is higher than that of ordinary one. Therefore, energy density and efficiency need be balanced. The energy density we proposed is a new evaluation index for electric machines. Energy density is defined as the multiplication of power density and torque density to evaluate the output performance of electric machine. It is necessary to study the iron loss of high energy density permanent magnet machine, which directly affects the efficiency. The traditional calculation method of iron loss of electric machine is based on Steinmetz formula and its extended equation [1-2]. Gordon R. Slemon and Richard
Bonert present a set of improved approximate models for the calculation of iron loss, considering the magnets, slots and poles [3-4]. Katsumi Yamazaki and Shukang Cheng proposed new methods respectively to reduce harmonic iron losses using rotor-shape optimization and magnet shape optimization [5-6]. Feng Chai and Peixin Liang had a research on prediction and calculation of iron losses in spoke-type permanent magnet synchronous machines [78]. Juha Pyrhonen had an in-depth study in iron loss analysis of permanent magnet synchronous machine based on finite element analysis over the electrical vehicle drive cycle, considering deep field weakening and short circuit iron loss [9]. Nicolas Denis studied a stator core made of nanocrystalline magnetic material, reducing core loss by 64 to $75 \%$ [10]. Mitja Breznik present that magnetic flux density behaviour in laminated electrical sheets which affects the results and precision of iron losses calculation of permanent magnet machine [11]. Qi Li present an analytical calculation method of iron loss for integral-slot interior permanent magnet synchronous machine by iron loss resistance, considering harmonic effect during flux weakening [12]. Naoki Minowa had a research on iron loss analysis of interior permanent magnet synchronous motors using dynamic hysteresis model represented by cauer circuit and 1-D finite-element method [13]. The DC bus voltage and harmonic components in the output voltage of the inverter can generate current ripples increasing the losses in the electric machine [14-15]. With a PWM DC$\mathrm{AC}$ inverter, the effect of load torque on iron losses was studied by considering three different driving conditions, including no-current, no-load and load conditions [16].

${ }^{1}$ School of Computer Science and Engineering, Tianjin University of Technology, Tianjin, 300384, China, ${ }^{2}$ Tianjin Key Laboratory for Advanced Mechatronic System Design and Intelligent Control, School of Mechanical Engineering, Tianjin University of Technology, Tianjin, 300384, China, ${ }^{3}$ National Demonstration Center for Experimental Mechanical and Electrical Engineering Education, Tianjin University of Technology, Tianjin, 300384, China, *corresponding author: zhengqingchun@tjut.edu.cn

https://doi.org/10.2478/jee-2021-0036, Print (till 2015) ISSN 1335-3632, On-line ISSN 1339-309X (C) This is an open access article licensed under the Creative Commons Attribution-NonCommercial-NoDerivs License (http://creativecommons.org/licenses/by-nc-nd/3.0/). 
Katsumi Yamazaki proposed a loss calculation method considering minor hysteresis loops for permanent magnet machines driven by pulse-width modulated inverters [17]. At present, few scholars have studied the loss analysis of high energy density permanent magnet machines powered by inverters.

The iron loss model of high energy density permanent magnet machine is established in this paper. The harmonic analysis, mathematical model and iron consumption calculation process of inverter input side are shown. Then the influence of size dimension of electric machine on the iron consumption is quantitatively analyzed, which is helpful to determine the size parameters. Finally, a high energy density machine was developed and it has a profound analysis in iron loss on calculated and experimental values.

\section{Iron loss model of high energy density permanent magnet machine}

\subsection{Harmonic analysis of electric machine}

For a conventional machine or a low energy density electric machine, due to the low saturation degree of magnetic circuit, harmonic current is generally ignored in order to simplify the calculation. It is considered that only fundamental current flows through the winding, recognizing the inverter current as ideal sinusoidal one.

In order to improve the torque and power density of main drive electric machine of electric propulsion system, the magnetic circuit is critically saturated, so the effect of harmonic magnetic field generated by harmonic current will be prominent. In the calculation of iron loss of main drive machine, the influence of harmonic current output by the inverter should be considered.

\subsection{Mathematical model of iron loss}

For permanent magnet machines with high magnetic saturation and inverter power supply, the traditional equivalent magnetic circuit method is used to calculate the magnetic density of the main propulsion motor, which will produce a large error. There is a big error in calculating the iron loss of high energy density machine by the traditional equivalent magnetic circuit method. In this paper, a mathematical model of iron loss is presented.

Considering harmonic effect of output current of inverters, eddy current and hysteresis loss densities [1-2] are given by

$$
\begin{gathered}
W_{\mathrm{e}}=\sum_{k=1}^{k_{\max }} k_{\mathrm{e}} k f_{1}^{2} B_{\mathrm{k}}^{2}, \\
W_{\mathrm{h}}=\sum_{k=1}^{k_{\max }} k_{\mathrm{h}} k f_{1} B_{\mathrm{k}}^{a\left(k f_{1} B_{\mathrm{k}}\right)} .
\end{gathered}
$$

The eddy current and hysteresis loss can be obtained by converting the above calculation method in the frequency domain to the time domain

$$
\begin{gathered}
P_{\mathrm{e}}=\frac{p}{2} \sum_{m=1}^{M} S_{\mathrm{m}} l_{\mathrm{Fe}} \frac{2 k_{\mathrm{e}}}{T} 2 \int_{0}^{T / 2}\left(\frac{\mathrm{d} B}{\mathrm{~d} t}\right)^{2} \mathrm{~d} t= \\
2 p N k_{\mathrm{e}} l_{\mathrm{Fe}} f_{1}^{2} \sum_{m=1}^{M}\left\{S _ { \mathrm { m } } \left[\sum_{n=1}^{N}\left(B_{m x, n}-B_{m x, n-1}\right)^{2}+\right.\right. \\
\left.\left.+\sum_{n=1}^{N}\left(B_{m y, n}-B_{m y, n-1}\right)^{2}\right]\right\}, \\
P_{\mathrm{h}}=\sum_{m=1}^{M} S_{\mathrm{m}} l_{\mathrm{Fe}} \frac{2 \pi k_{\mathrm{h}}}{T} \int_{0}^{T} B^{a-1} \frac{\mathrm{d} B}{\mathrm{~d} t} \mathrm{~d} t= \\
=2 \pi f_{1} k_{\mathrm{h}} l_{\mathrm{Fe}} \sum_{m=1}^{M} S_{m} B_{m, \max } .
\end{gathered}
$$

Iron loss can be calculated as $P_{\mathrm{Fe}}=P_{\mathrm{e}}+P_{\mathrm{h}}$. Combined with the magnetic density of the subdivision element calculated by finite element method, the iron consumption of the high energy density motor considering the inverter harmonic can be calculated according to the flow chart shown in Fig. 1.

Table 1. Basic parameters of electric machine

\begin{tabular}{lc}
\hline Electric machine parameter & Numerical value \\
\hline Rated power & $30 \mathrm{~kW}$ \\
Rated voltage & $260 \mathrm{~V}$ \\
Rated current & $140 \mathrm{~A}$ \\
Rated frequency & $400 \mathrm{~Hz}$ \\
Number of pole-pairs & 10 \\
Phase number & 3 \\
Stator slot number & 21 \\
Core length & $80 \mathrm{~mm}$ \\
Total weight & $16.8 \mathrm{~kg}$ \\
Rated energy density & 12.69 \\
\hline
\end{tabular}

\subsection{Physical model}

In this paper, a mathematical model of iron loss is presented. The parameters of high energy density permanent magnet synchronous machine analyzed in this paper are as follows: the number of slots is 21 , the number of poles is 20 , the maximum running speed is designed to be 2400 revolutions per minute, and the embedded structure is adopted. Since the main drive electric machine of electric propulsion system requires high energy density during normal operation, the permanent magnet machine adopts direct drive and semi-open ventilation structure. A three-phase fractional slot concentrated winding permanent magnet synchronous machine is designed. The basic parameters of high energy density machine designed are shown in Tab. 1. 


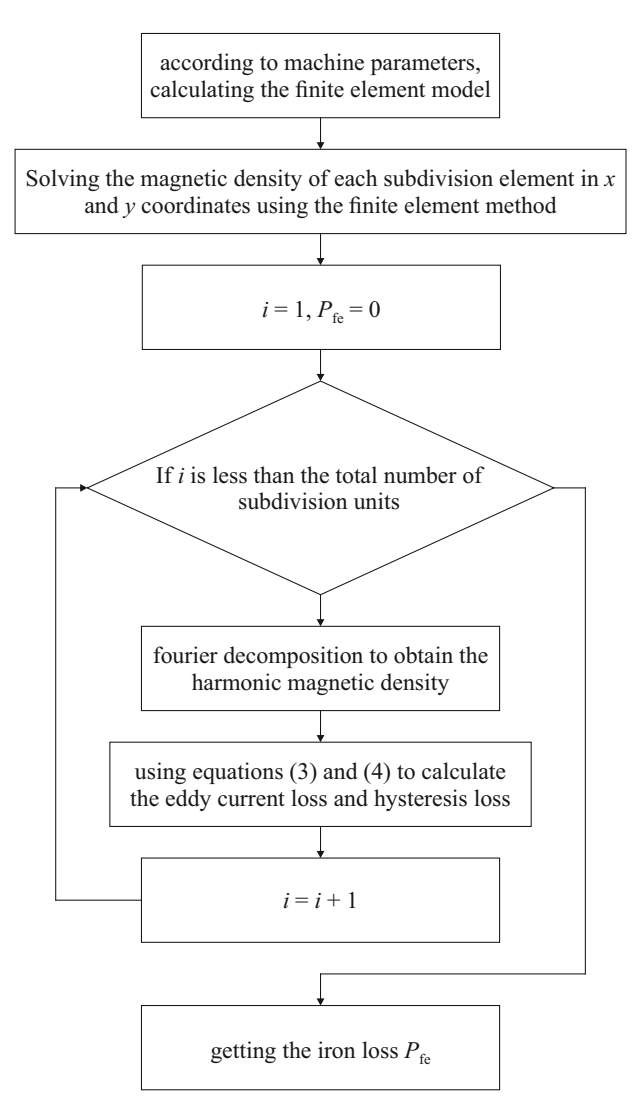

Fig. 1. Calculation process of iron loss of high energy density machine

When the rated load is obtained through finite element calculation, the magnetic density distribution of the high energy density permanent magnet machine of electric propulsion system is shown in Fig. 2. It can be seen that the highest magnetic density is located in the tooth and yoke of electric machine and the highest magnetic density reaches $1.4 \mathrm{~T}$, which is close to the saturation of magnetic density.

\section{Iron loss analysis of high energy density electric machine}

\subsection{Influence of stator outer radius on iron loss}

The thickness of stator yoke and rotor yoke has great influence on the magnetic density and energy density of high energy density machine. Under the same output conditions, when the thickness of yoke is larger, the magnetic density of yoke decreases and saturation decreases, but the volume and weight of electric machine increase. This leads to the change of iron loss and also directly affects the energy density of electric machine. Therefore, it is necessary to study the effect of rotor yoke thickness on iron loss.
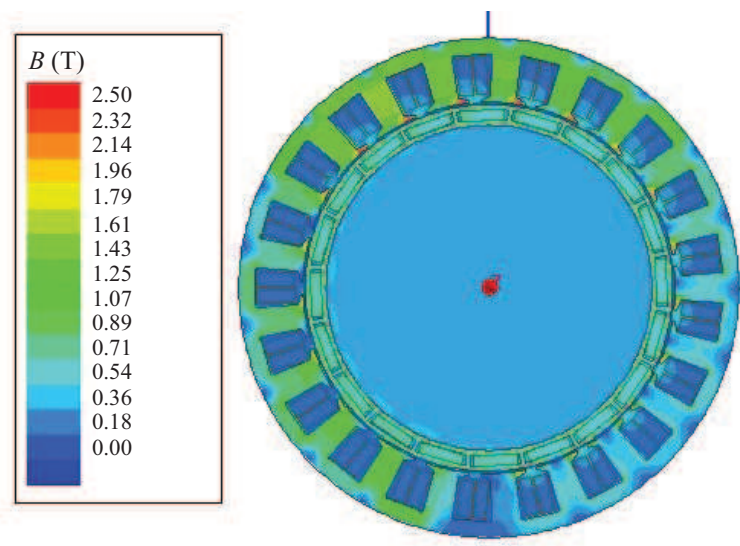

Fig. 2. Magnetic density distribution of electric machine

Based on magnetic density data of each subdivision unit calculated by the finite element method and the calculation flow is shown in Fig. 1, the total iron loss, eddy current loss and hysteresis loss at different rotor yoke thickness of high energy density permanent magnet machine powered by inverter are calculated.

The effect of the thickness of stator yoke on iron loss was studied. When the finite element method is used to calculate the magnetic density of machines with different stator yoke thickness, the rotor parameters, the slot area and tooth width of stator are kept unchanged and the stator outer diameter is changed.

Figure 3 shows the relationship between the total iron loss, the stator iron loss the rotor iron loss and the stator outer diameter. It can be seen that for the total iron loss and stator iron loss under no-load and load, as the outer diameter of stator increases, their values increase first and then decrease, and there is an extreme point. In designing the thickness of stator yoke, this extreme point should be avoided to reduce the iron loss. In addition, in order to reduce the weight of electric propulsion system machine, the thickness of stator yoke should be selected in the range below the extreme point. For example, the radius of stator outer diameter should be less than $110 \mathrm{~mm}$ in Fig. 3. However, proper value of stator yoke thickness should be combined with torque and power of electric machine.

As can be seen from Fig. 3, for the same thickness of stator yoke, compared with no-load, the total iron loss and stator iron loss of load increased significantly, but the rotor iron loss changed little. This is because the fundamental magnetic density increases obviously under load, while the harmonic magnetic density also increases but it is not obvious. The stator iron loss is mainly caused by the fundamental magnetic density, while the rotor iron loss is mainly caused by the harmonic magnetic density. In addition, the iron loss of rotor increases with the increase of the thickness of stator yoke, but the increase is not obvious.

The relationship between the stator eddy current loss, the rotor eddy current loss and the thickness of stator outer radius is shown in Fig. 4. The relationship between 


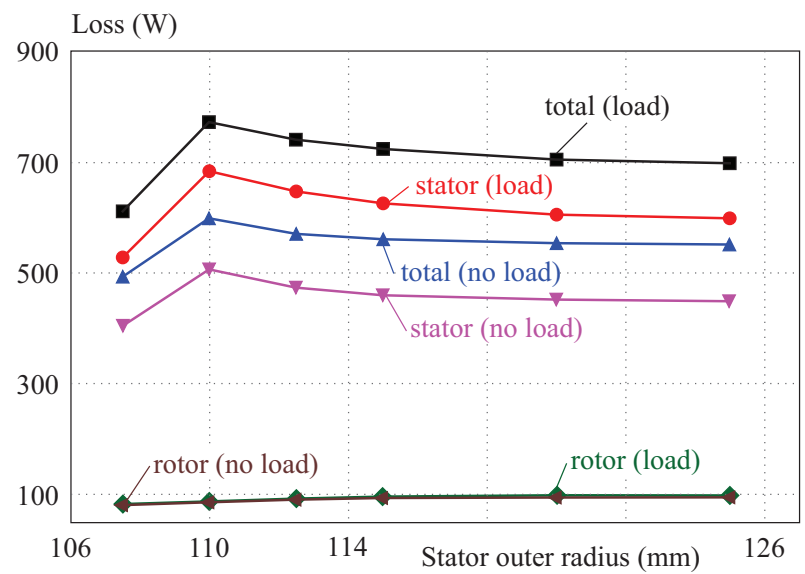

Fig. 3. Relation between stator outer radius and iron loss

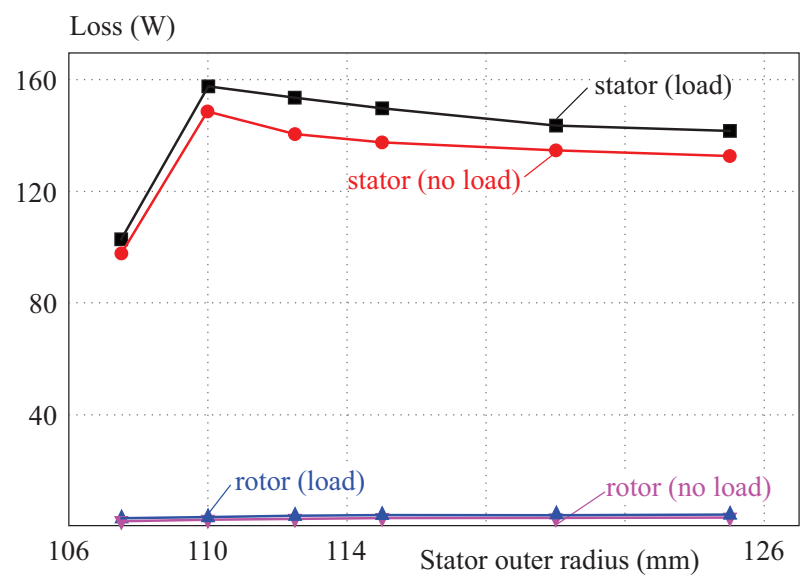

Fig. 5. Relation between hysteresis loss and stator outer radius

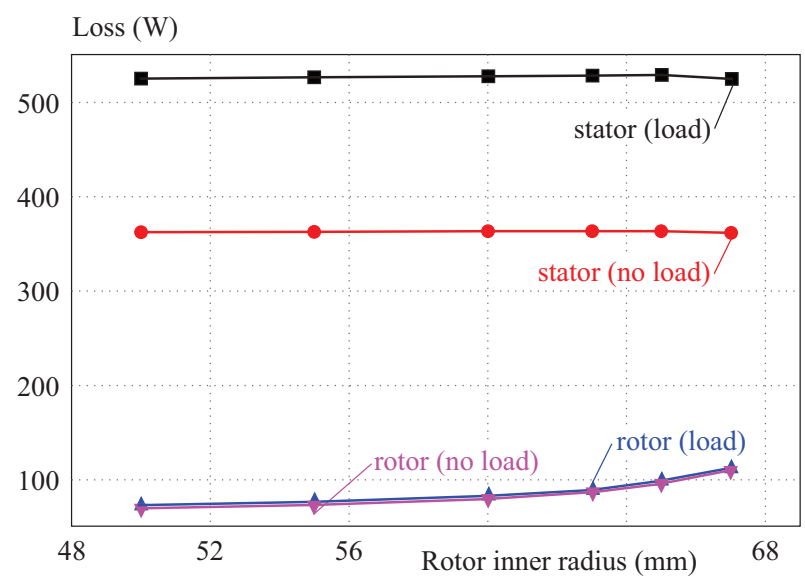

Fig. 7. Relation between eddy current loss and rotor inner radius

stator hysteresis loss, rotor hysteresis loss and the thickness of stator yoke is shown in Fig. 5. It can be seen that the stator eddy current loss and hysteresis loss have maximum value while the rotor eddy current loss and hysteresis loss increase with the increase of the yoke thickness with a small slope.

By comparing Fig. 4 and Fig. 5, for the same stator outer diameter, the eddy current loss of stator is much

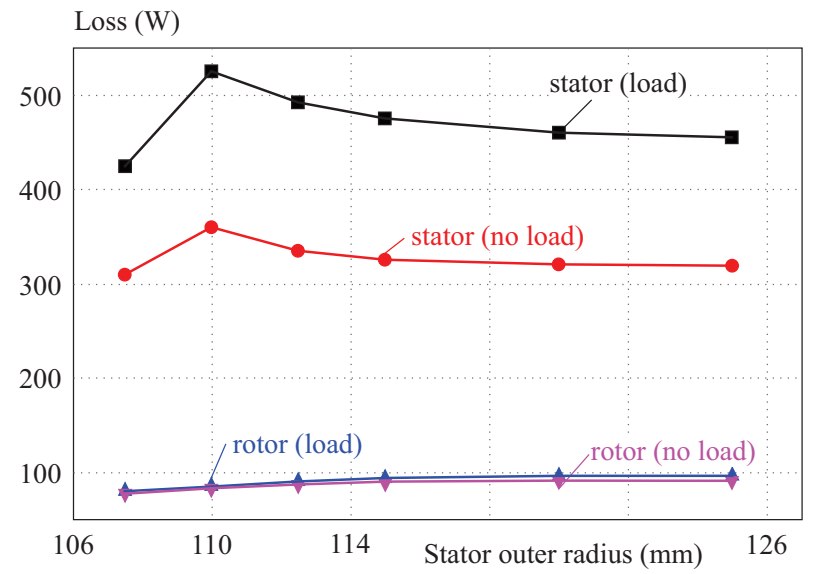

Fig. 4. Relation between eddy current loss and stator outer radius

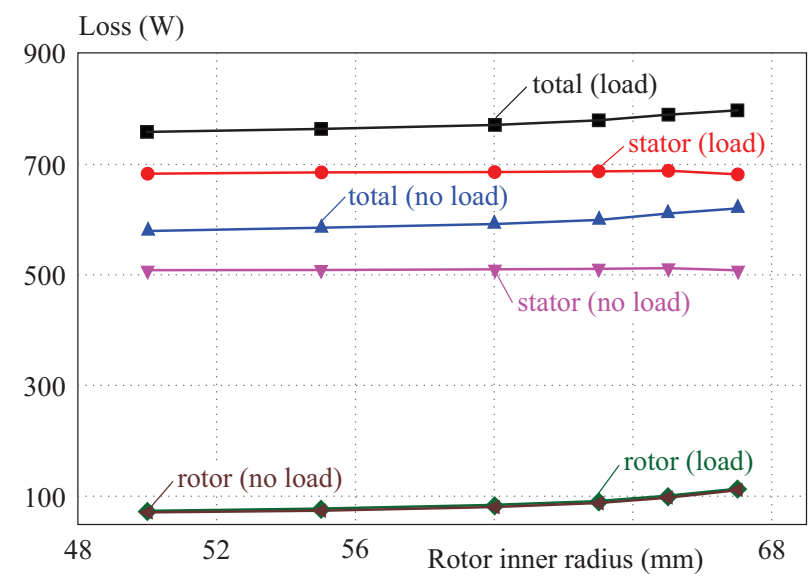

Fig. 6. Relation between rotor inner radius and iron loss

larger than the hysteresis loss. Therefore, it can be seen that the eddy current loss is the main part of iron loss. Therefore, when designing stator and rotor of high energy density permanent magnet machine, a laminated structure as thin as possible should be adopted to reduce the iron loss.

\subsection{Influence of rotor inner radius on iron loss}

The effect of the thickness of rotor yoke on iron loss was studied. When the finite element method is used to calculate the magnetic density with different inner diameters of rotor, the stator parameters, rotor outer diameter and permanent magnet thickness are kept unchanged and the rotor inner diameter is changed. The total iron loss, stator iron loss and rotor iron loss are calculated as shown in Fig. 6. It can be seen that the total iron loss and rotor iron loss increase with the decrease of rotor yoke thickness, while the stator iron loss remains unchanged. When the thickness of the rotor yoke decreases to a certain extent, the speed of total iron loss and rotor iron loss increase will be accelerated. Therefore, when selecting the inner diameter of rotor, it should not be too small to avoid the demagnetization failure caused by the rapid increase of iron loss and high temperature rise of rotor. 


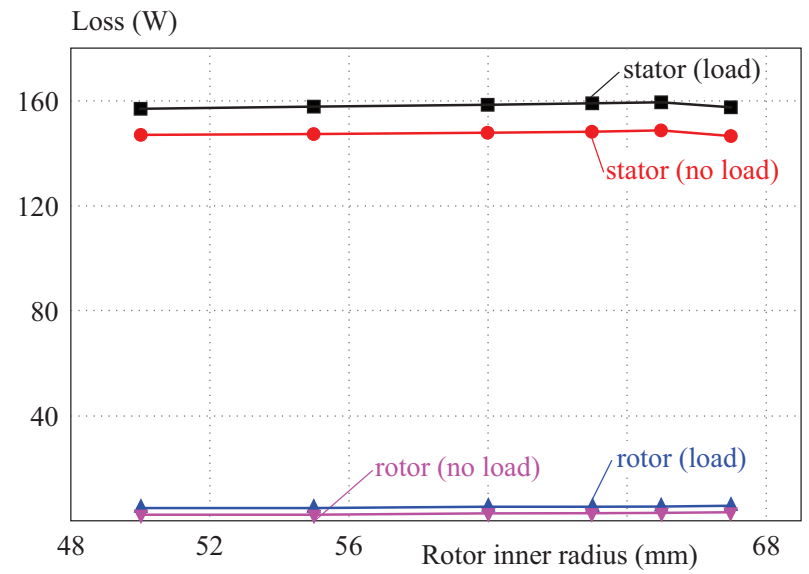

Fig. 8. Relation between hysteresis loss and rotor inner radius

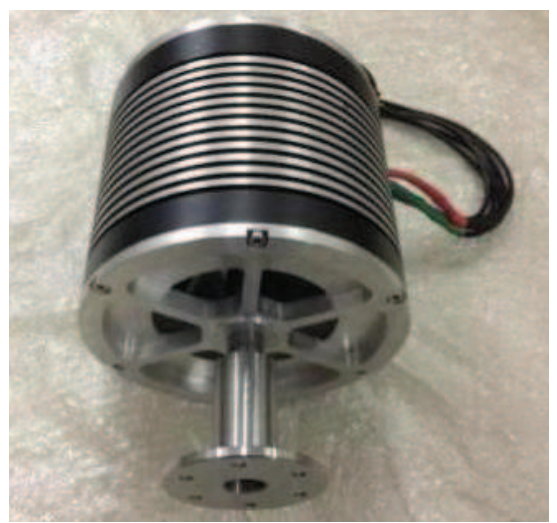

Fig. 9. High energy density permanent magnet machine

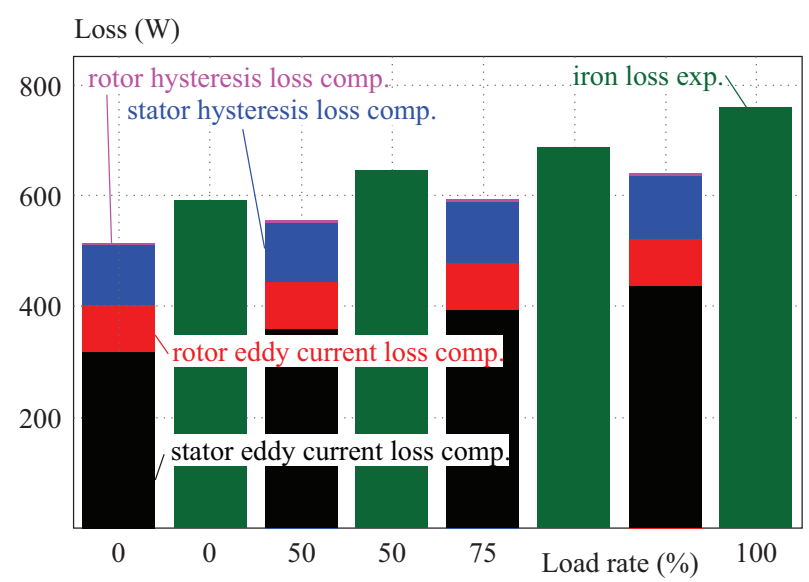

Fig. 10. Calculated and experimental values of iron consumption at different load rates

The relationship between the stator eddy current loss, the rotor eddy current loss and the thickness of rotor inner radius is shown in Fig. 7. The relationship between stator hysteresis loss, rotor hysteresis loss and the thickness of rotor inner radius is shown in Fig. 8. It can be seen that the stator eddy current loss and hysteresis loss remain unchanged, while the rotor iron eddy current loss increases with the increase of rotor inner radius, but rotor hysteresis loss does not change significantly.

In order to reduce the iron loss of electric machine, according to the above analysis, the radius of stator outer diameter can be selected as $107.5 \mathrm{~mm}$ and the radius of rotor inner diameter as $64 \mathrm{~mm}$ for the electric machine in this paper.

\subsection{Analysis of iron loss of high energy density machine under different loads}

The rated power of the prototype studied in this paper is $30 \mathrm{~kW}$, and enclosed stator structure and transparent rotor structure are adopted. The developed prototype is shown in Fig. 9.

In this paper, the experimental platform of high energy density permanent magnet machine for electric propulsion system is built for no-load and load experiments.

The high energy density permanent magnet machine of electric propulsion system is tested and the core loss test results of prototype are obtained respectively under no load and load. As shown in Fig. 10, simulation analysis and measured data of iron loss of prototype under load rates of $0 \%, 50 \%, 75 \%$ and $100 \%$ are shown. Among them, the maximum error between the calculated iron loss value and the experimental value is the rated load stage, with an error of $15.52 \%$. The smallest error is in no-load stage and the error reaches $12.98 \%$.

\section{Conclusion}

Firstly, the harmonic effect of inverter output is analyzed and the magnetic field character of high energy density permanent magnet machine is analyzed. Then the iron loss analysis model is established. The calculation process of iron loss of electric machine is presented. The main conclusions are as follows.

The magnetic density of the high energy density permanent magnet machine is up to $1.4 \mathrm{~T}$, and the highest position is on the stator teeth.

Eddy current loss is the main component of iron loss of high energy density permanent magnet machine in electric propulsion system. With the increase of stator outer diameter, stator eddy current loss first increases and then decreases, while rotor eddy current loss is not obvious. Hysteresis loss increases first and then decreases.

With the increase of rotor diameter, the iron loss of high energy density permanent magnet machine in electric propulsion system increases slightly, but the change is not obvious. Among them, rotor eddy current loss tends to increase.

\section{Acknowledgment}

This study was supported by the National Natural Science Foundation of China (51607115 and 61941305) 
and the Tianjin Science and Technology Project (19YFFCYS00110).

\section{REFERENCES}

[1] A. Krings and J. Soulard, "Overview and Comparison of Iron Loss Models for Electrical Machines", J. Elect. Eng., vol. 10, no. 3, pp. 162 169, Jun. 2010.

[2] A. Boglietti, A. Cavagnino, and M. Lazzari, "Predicting iron losses in soft magnetic materials with arbitrary voltage supply: an engineering approach", IEEE Trans. Magn., vol. 39, no. 2, pp. 981989, Feb. 2003.

[3] C. C. Mi, G.R. Slemon, and R. Bonert, "Modeling of iron losses of permanent-magnet synchronous motors", IEEE Trans. Ind. Appl., vol. 39, no. 3, pp. 734742, Mar. 2003.

[4] C. C. Mi, G. R. Slemon, and R. Bonert, "Minimization of iron losses of permanent magnet synchronous machines", IEEE Trans. Energy Conv., vol. 20, no. 1, pp. 121127, Jan. 2005.

[5] K. Yamazaki and H. Ishigami, "Rotor-Shape Optimization of Interior- Permanent-Magnet Motors to Reduce Harmonic Iron Losses", IEEE Trans. Ind. Elect., vol. 57, no. 1, pp. 6169, Jan. 2009.

[6] F. Chai, P. Liang, and Y. Pei, "Magnet Shape Optimization of Surface- Mounted Permanent-Magnet Motors to Reduce Harmonic Iron Losses", IEEE Trans. Magn., vol. 52, no. 7, pp. 14, Jul. 2016.

[7] P. Liang, F. Chai, and L. Chen, "Analytical Prediction of No-Load Stator Iron Losses in Spoke-Type Permanent-Magnet Synchronous Machines", IEEE Trans. Energy Conv., vol. 33, no. 1, pp. 252259, Jan. 2018.

[8] P. Liang, Y. Tang, and F. F. Chai, "Calculation of the Iron losses in a Spoke-Type Permanent Magnet Synchronous In-Wheel Motor for Electric Vehicles by Utilizing the Bertotti Model", IEEE Trans. Magn., vol. 55, no. 7, pp. 17, Jul. 2019.

[9] V. Ruuskanen, J. Nerg, and M. Rilla, "Iron Loss Analysis of the Permanent-Magnet Synchronous Machine Based on Fi-nite-Element Analysis Over the Electrical Vehicle Drive
Cy-cle", IEEE Trans. Ind Elect., vol. 63, no. 7, pp. 41294136, Jul. 2016.

[10] N. Denis, M. Inoue, and K. Fujisaki, "Iron Loss Reduction of Permanent Magnet Synchronous Motor by Use of Stator Core Made of Nanocrystalline Magnetic Material", IEEE Trans. Magn., vol. 53, no. 11, pp. 16, Nov. 2017.

[11] M. Breznik, V. Gorican, and A. Hamler, "Analysis and identification of influential phenomena on iron losses in embedded permanent magnet synchronous machine", J. Elect. Eng., vol. 68, no. 1, pp. 2330, Jan. 2017.

12] Q. Li, T. Fan, and X. Wen, "Characterization of Iron Loss for Integral-Slot Interior Permanent Magnet Synchronous Machine During Flux Weakening", IEEE Trans. Magn., vol. 53, no. 5, pp. 18, May. 2017.

[13] N. Minowa, Y. Takahashi, and K. Fujiwara, "Iron Loss Analysis of Interior Permanent Magnet Synchronous Motors Using Dynamic Hysteresis Model Represented by Cauer Circuit", IEEE Trans. Magn., vol. 55, no. 6, pp. 14, Jun. 2019.

[14] N. Denis, Y. Wu, and K. K. Fujisaki, "Impact of the Inverter DC Bus Voltage on the Iron Losses of a Permanent Magnet Synchronous Motor at Constant Speed", IEEJ J. Ind. Appl., vol. 6, no. 6, pp. 346352, Dec. 2017.

[15] P. Sergeant, H. Vansompel, and A. Hemeida, "A computa-tionally efficient method to determine iron and magnet losses in VSI-PWM fed axial flux permanent magnet synchronous machines", IEEE Trans. Magn., vol. 50, no. 8, pp. 110, Aug. 2014.

[16] N. G. Thao, N. Denis, and Y. Wu, "Study of the Effect of Load Torque on the Iron Losses of Permanent Magnet Motors by using Finite Element Analysis", IEEJ J. Ind. Appl., vol. 8, no. 3, pp. 522531, Jun. 2019.

[17] K. Yamazaki and Y. Takaki, "Iron Loss Analysis of Permanent Magnet Motors by Considering Minor Hysteresis Loops Caused by Inverters", IEEE Trans. Magn., vol. 55, no. 6, pp. 14, Jun. 2019 .

Received 4 May 2021 